\title{
Implementasi dan Uji Kinerja Kontrol PID untuk kestabilan Pesawat Tanpa Awak Tail-sitter pada Keadaan Mengambang
}

\author{
Taufiq Nuzwir Nizar1 ${ }^{*}$, Didit Andri Jatmiko², Rodi Hartono³, Agung Ibnu Ghani Pratama4 \\ 1,4) Program Studi Sistem Komputer \\ 2) Program Studi Teknik Informatika \\ 3) Program Studi Teknik Elektro, \\ $1,2,3,4)$ Fakultas Teknik dan Ilmu Komputer, Universitas Komputer Indonesia \\ Jl. Dipati Ukur No. 112 - 116, Bandung, Indonesia 40132 \\ *email: taufiq.nuzwir@email.unikom.ac.id
}

\begin{abstract}
ABSTRAK - Pesawat tail-sitter adalah pesawat tanpa awak yang dapat lepas landas secara vertical, pesawat ini merupakan penggabungan antara pesawat fix wing dengan rotary wing yang bertujuan agar memerlukan sumber daya yang kecil pada saat terbang dan area yang kecil pada saat lepas landas dan mendarat. salah satu faktor keberhasilan terbang pesawat tanpa awak tail-sitter adalah kestabilan pada saat lepas landas hingga mengambang sebelum transisi untuk terbang secara horizontal. salah satu masalah yang dapat mengganggu kestabilan pada pesawat tanpa awak tail-sitter adalah adanya ketidakseimbangan pada aktuator seperti putaran motor dan pergerakan servo stabilizer. Untuk mengatasi masalah tersebut pada Penelitian ini akan membuat sistem pengendalian agar pesawat tanpa awak tail-sitter, tujuannya agar dihasilkan sistem kendali pesawat tanpa awak yang stabil pada keadaan mengambang saat melakukan lepas landas dan mendarat. Metode pengendalian yang telah digunakan adalah kontrol Proportional Integral Derivative (PID). Sensor yang digunakan adalah akselerometer dan giroskop yang dapat membaca pergerakan dan perubahan sudut pada pesawat tanpa awak tail-sitter. Dari hasil pengujian dan analisa pemberian parameter Kp :2,5, Ki : 0,250, dan Kd: 23 untuk kendali pitch dan Roll memerikan hasil yang baik, yaitu pesawat tanpa awak tail-sitter dapat terbang dan mempertahankan kestabilan nya pada saat mengambang. Kata Kunci - tail-sitter; kendali; PID; mengambang/hovering; IMU
\end{abstract}

\section{Implementation and Performance Testing of PID Control for Stability Unmanned Aerial Vehicle Tail-sitter in Hovering Condition}

\begin{abstract}
The tail-sitter is an unmanned aerial vehicle (UAV) that can fly vertically. This UAV is a combination of a fixed wing with a rotary wing which aims to require a small resource during flight and a small area during takeoff and landing. One of the success factors of flying an unmanned aerial vehicle tail-sitter is stability during takeoff to hovering before the transition to flying horizontally. One of the problems that can interference with the stability of the tail-sitter UAV is the imbalance of actuators such as motor rotation and servo stabilizer movement. To resolve this problem, an operating technique is required on the actuator to keep the unmanned aerial vehicle tail-sitter stable. The control method used is Proportional Integral Derivative (PID) control. The sensor used are accelerometer and gyroscope sensors that can read the movements and angles of unmanned aerial vehicle tail-sitter. From the test results and analysis of the parameters Kp: 2.5, Ki: 0.250, and Kd: 23 for Pitch and Roll control yields good results, there the tail-sitter UAV can fly and maintain its stability during the hovering phase.
\end{abstract}

Keywords - tail-sitter; cControl; PID; hovering; IMU

\section{Pendahuluan}

Pesawat tanpa awak secara garis besar terbagi menjadi 2 jenis yaitu fixed wing dan rotary wing. Pada pesawat fixed wing memiliki keunggulan sumber daya yang kecil pada saat terbang akan tetapi memerlukan area lepas landas dan mendarat yang luas, sedangkan pada jenis rotary wing memerlukan area yang kecil pada saat lepas landas dan mendarat akan tetapi memerlukan sumber daya yang besar pada saat terbang [1]. Salah satu tantangan dalam pengembangan pesawat tanpa awak adalah bagaimana mengembangkan pesawat yang memerlukan sumber daya yang kecil dan dapat lepas 
landas dan mendarat di area yang kecil [2]. Salah satu solusinya adalah pesawat tail-sitter yang merupakan penggabungan antara pesawat tanpa awak berjenis rotary wing dan fixed wing [3 - 5]. Penggabungan dua jenis pesawat tanpa awak ini bertujuan untuk menciptakan sebuah pesawat tanpa awak yang lebih andal, salah satu contoh keunggulan dari tail-sitter ini yaitu bisa melakukan lepas landas dan mendarat di area yang terbatas [6],[7]. System ini melakukan lepas landas secara vertikal lalu fase mengambang seperti pesawat tanpa awak rotary wing hingga kemudian terbang secara horizontal layaknya fixed wing, lalu mendarat secara vertikal kembali seperti diilustrasikan pada gambar 1 .

Proses lepas landas hingga mendarat ini membutuhkan kestabilan yang baik, terutama pada saat fase lepas landas hingga mengambang di ketinggian tertentu, karena hal ini merupakan salah satu faktor keberhasilan dari proses lepas landas sebelum terbang secara horizontal dan juga sebaliknya untuk proses mendarat. Salah satu masalah pada kestabilan yang sering terjadi pada pesawat tanpa awak yaitu efek rotasi yang berasal dari putaran baling-baling dan perbedaan gaya dorong pada motor dan gangguan luar seperti angin yang dapat mengganggu sikap pada pesawat tanpa awak.

Efek rotasi dan gangguan luar ini harus diminimalkan oleh suatu sistem kendali, teknik kendali yang akan digunakan adalah kontrol PID
(Proportional Integral Derivative) [8],[9] . Prinsip kerja kontrol PID adalah menggunakan error yang didapat sebagai aksi yang digunakan untuk memperbaiki error yang terbaca [10],[11].

Berdasarkan uraian masalah di atas maka tujuan dari penelitian ini adalah untuk merancang suatu sistem kendali yang andal yang dapat mengontrol dan mengatasi masalah kestabilan pada sebuah pesawat tanpa awak tail-sitter, metode yang digunakan untuk mengendalikan sistem ini menggunakan metode PID.

\section{METODE DAN BAHAN}

\subsection{Kendali PID}

Kontrol PID merupakan salah satu jenis kontrol yang telah umum digunakan pada dunia industri. Pengontrol PID akan memberikan aksi berdasarkan error yang telah diperoleh[12]. Error adalah perbedaan dari set point yang telah ditentukan. Penjelasan mengenai komponen PID dapat dilihat pada gambar 2.

Kontrol PID terdapat tiga komponen utama yaitu kontrol P (Proportional), kontrol I (Integral), dan kontrol D (Derivative) [12]. Komponen-komponen tersebut bertujuan untuk mempercepat reaksi sebuah sistem, menghilangkan offset dan menghasilkan perubahan awal yang besar. Keluaran dari kontroler PID adalah hasil penjumlahan dari ketiga komponen tersebut. Karakteristik kontroler PID ini dipengaruhi

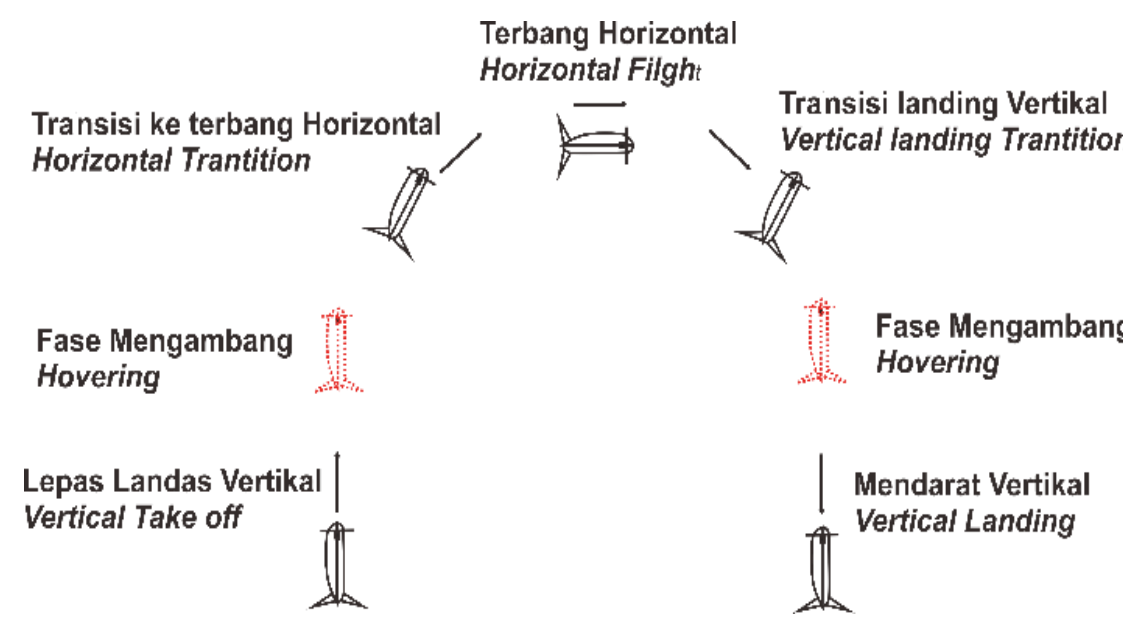

Gambar 1. Proses terbang pesawat tail-sitter

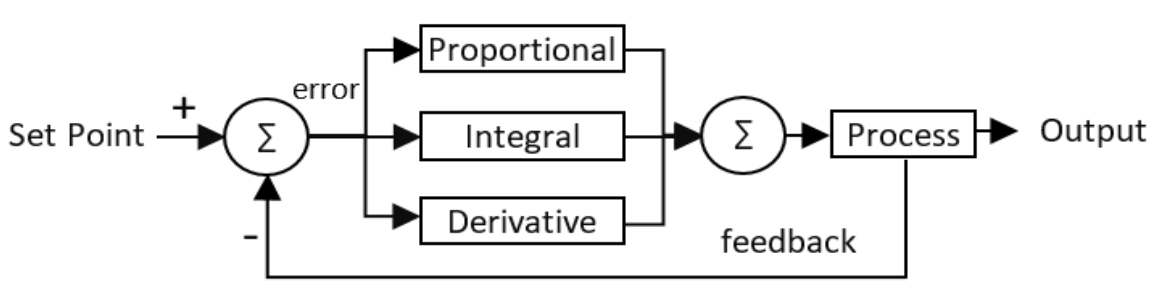

Gambar 1. Diagram blok PID dengan Closed loop [12] 
oleh ketiga komponen $\mathrm{P}$, I, dan $\mathrm{D}$, penyetelan nilai setiap konstanta $\mathrm{Kp}, \mathrm{Ki}$, dan Kd akan mengakibatkan penonjolan sifat dari masing-masing komponen. Karakteristik dari kontroler PID dan hubungan sinyal error dan sinyal kontrol dapat dinyatakan pada persamaan 1 [13].

$u(t)=K p\left[e(t)+\frac{1}{{ }^{\prime} I} \int e(t) d t+{ }^{\prime} D \frac{d}{d t} e(t)\right]$

Pada perancangan sistem kontrol PID, biasanya dilakukan dengan metode trial $\mathcal{E}$ error. Hal ini disebabkan karena parameter $\mathrm{Kp}, \mathrm{Ki}$ dan Kd tidak independent, untuk mendapatkan aksi kontrol yang baik diperlukan langkah trial $\mathcal{E}$ error dengan kombinasi antara $\mathrm{P}$, I dan D sampai ditemukan nilai Kp, Ki dan Kd seperti yang diharapkan [14].

\subsection{Pergerakan dasar dari pesawat tanpa awak Tail-sitter}

Pergerakan dasar pesawat tail-sitter ini mengacu pada pergerakan sumbu 3 derajat yang dikenal dengan pergerakan sikap roll, pitch, dan yaw [15],[16]. Gambar 3 merupakan ilustrasi dari pergerakan dasar pesawat tanpa awak tail-sitter.

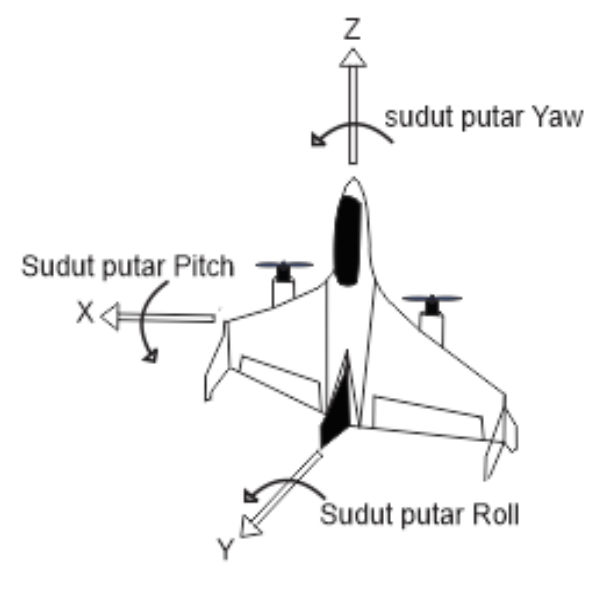

Gambar 3. Sumbu pergerakan tail-sitter

Gambar 4 merupakan ilustrasi pergerakan sikap roll pada pesawat, pergerakan dari sikap roll ini disebabkan oleh perbedaan salah satu kecepatan motor. Roll kanan terjadi akibat putaran motor nomor 1 lebih cepat dari putaran motor 2. Begitu pula sebaliknya untuk roll kiri. Pergerakan lainnya adalah sikap pitch yaitu pada sumbu $x$ terjadi akibat gerakan searah dari fin Stabilizer/ elevon. Ilustrasi gerakan pitch ditunjukkan pada gambar 5. Berdasarkan Gambar 5, pitch ke belakang terjadi akibat fin Stabilizer/ elevon bergerak ke depan, dan untuk pitch ke depan ini terjadi akibat fin Stabilizer/ elevon bergerak ke belakang.

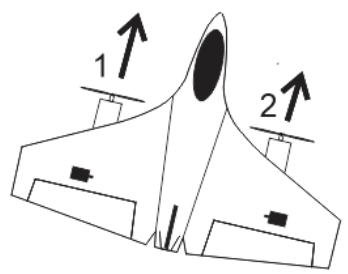

Roll Kanan

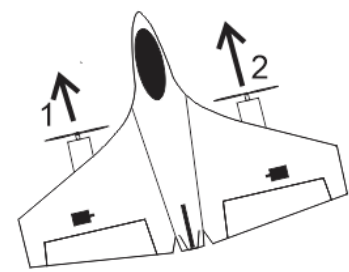

Roll Kiri

Gambar 4. Pergerakan Roll Kanan dan Kiri

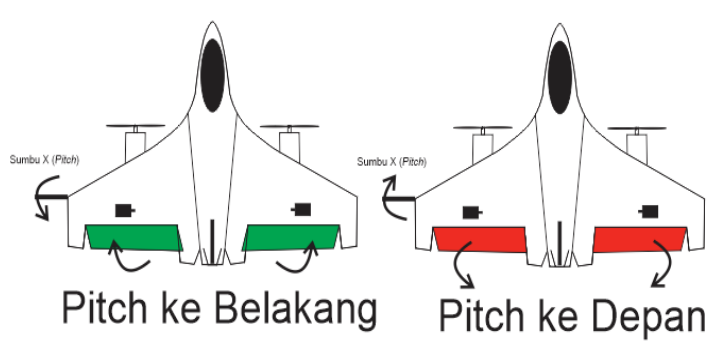

Gambar 5. Pergerakan pitch Belakang dan Depan

Pergerakan dari sikap yaw pada sumbu z terjadi akibat gerak berlawanan dari fin Stabilizer/elevon, yaw kanan terjadi akibat fin Stabilizer/ elevon kanan bergerak ke belakang dan fin Stabilizer/ elevon kiri bergerak ke depan, begitu pula sebaliknya untuk yaw kiri. Ilustrasi sikap yaw dapat dilihat pada gambar 6.

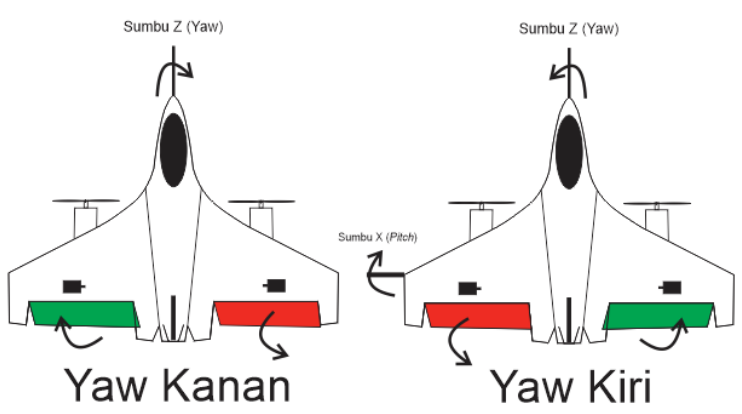

Gambar 6. Pergerakan yaw kanan dan yaw kiri

\subsection{Perancangan Desain dan Mekanik}

Perancangan desain dilakukan untuk menggambarkan penempatan komponen dan mekanik yang akan digunakan. Berikut rancangan desain akan ditunjukkan pada gambar 7. Bentuk pesawat memiliki sayap yang lebar berfungsi agar pesawat dapat lebih stabil pada saat terbang. Penggerak menggunakan 2 buah motor brushless yang di pasangkan di masing-masing sayap, fungsi penggerak ini memiliki 2 fungsi yaitu sebagai penggerak pada saat terbang dan sebagai rotary wing pada saat lepas landas dan mendarat. Untuk mengendalikan pesawat pada saat terbang dan 
lepas landas atau mendarat menggunakan fin stabilizer pada bagian belakang masing-masing sayap yang digerakkan menggunakan motor servo.

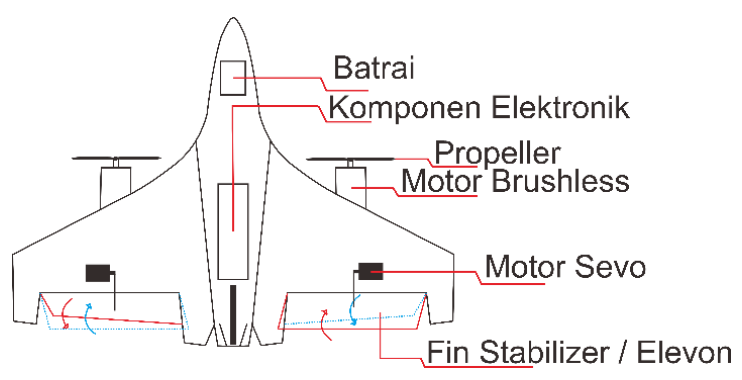

Gambar 7. Rancangan desain penempatan komponen dan mekanik

\subsection{Perancangan Sistem Kendali}

Pada proses kendali, besarnya gaya dorong oleh putaran motor dan pergerakan fin Stabilizer/elevon diperlukan untuk menghasilkan sikap pergerakan dari pesawat tanpa awak tail-sitter, sikap pergerakan ini menjadi nilai besaran (variabel, parameter) yang harus mendekati nilai yang diinginkan, maka dari itu pada penelitian ini jenis sistem kendali yang digunakan adalah jenis closed loop[8] karena adanya umpan balik yang dapat mempengaruhi proses kendali. Desain diagram blok sistem kendali closed loop ditampilkan pada gambar 8 .

Pada gambar 8 set point merupakan nilai derajat roll, pitch, yaw yang diinginkan, pada kasus ini set point yang diinginkan adalah bernilai 0 derajat. Controller, yang bertugas sebagai pemroses kendali yang mengatur aktuator untuk agar posisi pesawat berada pada kondisi set point. Pesawat akan mengalami gangguan dari luar berupa angin, oleh karena itu keadaan posisi pesawat akan dijadikan feedback masukan dan akan dibandingkan dengan nilai set point.

\subsection{Perancangan Perangkat Keras}

Diagram blok sistem dari penelitian ini menggambarkan rancangan perangkat keras sistem yang dibuat. Diagram blok sistem dapat dilihat pada gambar 9. Sensor IMU (Inertia Measurement Unit) digunakan untuk mengukur perubahan sudut yang terjadi pada pesawat tanpa awak tail-sitter. Pada sistem yang dirancang, sensor akan memberikan hasil data pengukuran sensor Accelerometer, Gyroscope dalam 3 axis $(\mathrm{x}, \mathrm{y}, \mathrm{z})$ yang kemudian diolah menjadi data perubahan sudut. Sensor IMU yang digunakan pada penelitian ini adalah sensor MPU6050. Rc receiver merupakan perangkat penerima sinyal dari remote control, pada sistem ini, perangkat penerima ini memiliki peran untuk mengubah sinyal remote control menjadi masukan PWM ke mikrokontroler. Mikrokontroler ini akan digunakan untuk menanamkan algoritma kontrol. Selain berisikan algoritma kendali. Mikrokontroler yang digunakan pada perancangan alat ini adalah mikrokontroler arduino nano dengan chip Atmega328AU. ESC (Electronic Specs Controller) merupakan driver motor untuk mengatur kecepatan motor brushless. Motor Servo mempunyai peranan sebagai penggerak fin stabilizer. Motor Brushless DC memiliki peran sebagai penghasil daya dorong untuk pesawat tail-sitter. Motor brushless menghasilkan daya dorong dari putaran baling-baling.

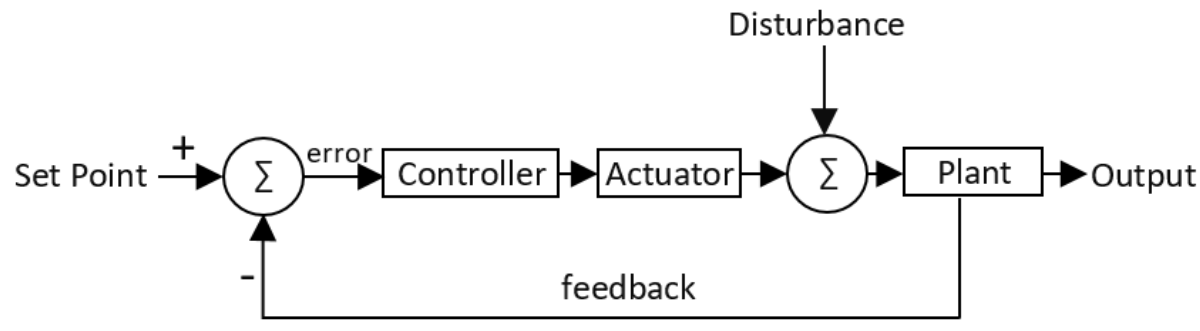

Gambar 8. Diagram blok sistem kendali

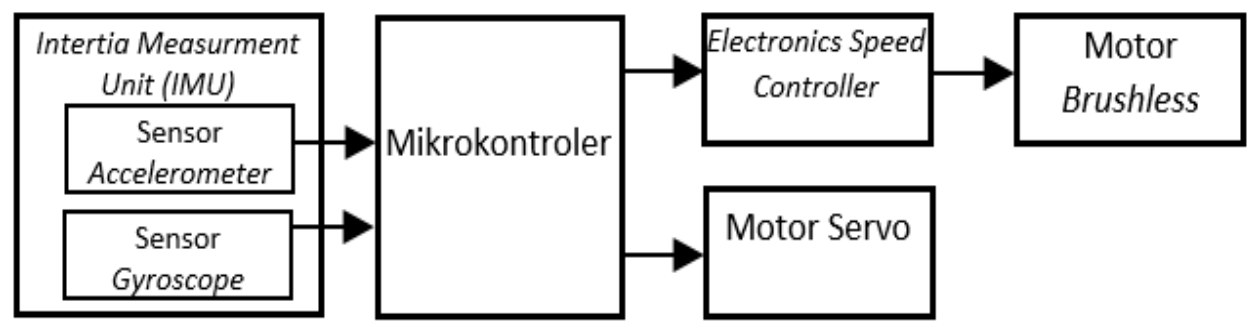

Gambar 9. Diagram blok perangkat keras 


\subsection{Perancangan Perangkat Lunak}

Pada perancangan perangkat lunak ini akan dilakukan implementasi algortima kendali yang telah dibuat ke dalam perangkat mikrokontroler. Secara garis besar pada sistem yang dibuat terdapat 2 bagian perangkat lunak yang paling penting dalam sistem ini yaitu komponen perangkat lunak untuk pembacaan dan pengolahan sikap atau kondisi pesawat tail-sitter yang berfungsi untuk menjaga posisi pesawat agar tetap pada posisi yang diharapkan.

Gambar 10 menunjukkan algoritma pengolahan sikap pesawat pada saat keadaan terbang, langkah pertama melakukan inisialisasi dan mengambil data sensor akselerometer dan gyroscope. Selanjutnya menentukan arah sudut ROLL, PITCH dan YAW berdasarkan percobaan agar kondisi pesawat sesuai dengan arah yang diharapkan. Selanjutnya data sensor dengan data pengaturan akan dikalkulasi dan dilakukan pengontrolan pada aktuator agar datanya mendekati atau sama.

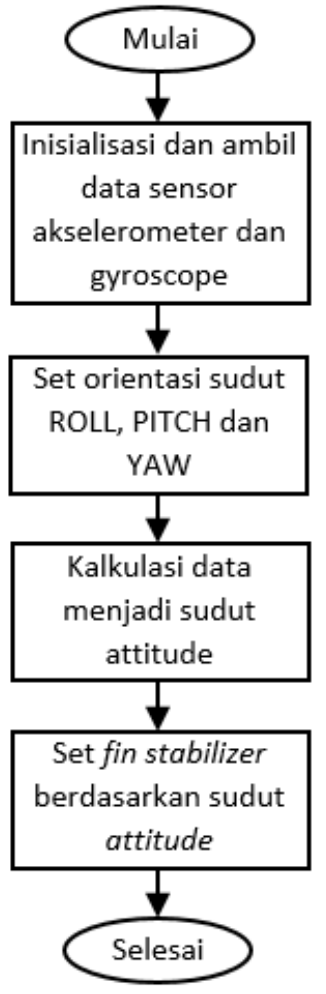

Gambar 10. Diagram Alir Pembacaan dan Pengolahan Sikap tail-sitter

\subsection{Diagram Alir kendali dengan PID}

Pengontrolan yang cepat untuk mengkondisikan dari gangguan lingkungan perlu dilakukan agar pesawat dapat berada pada kondisi yang diharapkan dan selalu dalam keadaan stabil pada saat mengambang. Pengontrolan yang digunakan menggunakan kontol PID. Berikut ini adalah penjelasan dari diagram alir proses kendali PID.

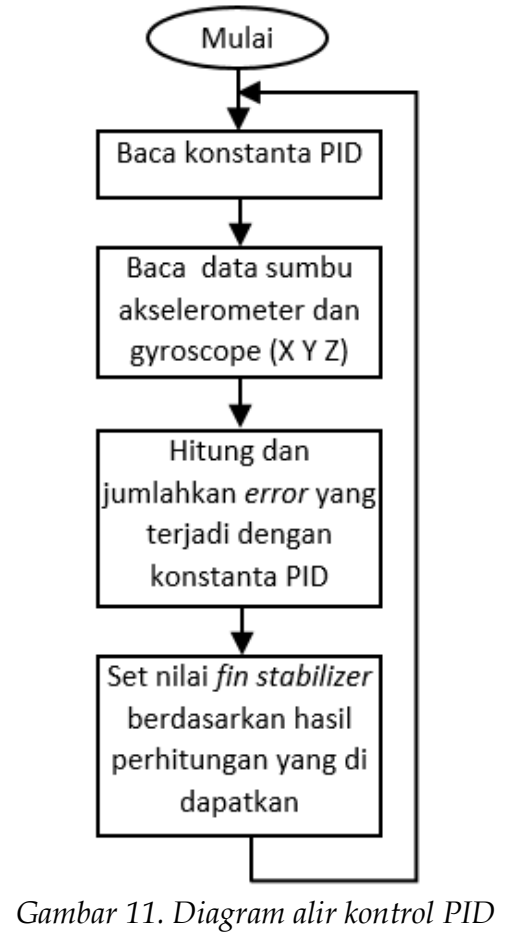

Gambar 11 menunjukkan algoritma pengontrolan pesawat menggunakan PID. Langkah awal menentukan konstanta PID. Nilai konstanta PID didapatkan dengan cara percobaan sampai didapatkan nilai yang terbaik. Selanjutnya dilakukan pembacaan sensor akselerometer dan giroskop kemudian nilai dari sensor di bandingkan dengan konstanta PID dan dilakukan kalkulasi error. Nilai hasil kalkulasi dijadikan keluaran untuk pengontrol posisi fin stabilizer yang bertujuan agar pesawat tidak berputar pada saat kondisi mengambang.

\section{HASIL DAN PEMBAHASAN}

\subsection{Pengujian Sensor}

Pengujian sensor adalah pengujian untuk mengetahui akurasi data sensor tersebut. Pengujian sensor dilakukan dengan membandingkan nilai hasil pengolahan sensor MPU6050 dengan alat ukur berupa busur derajat.

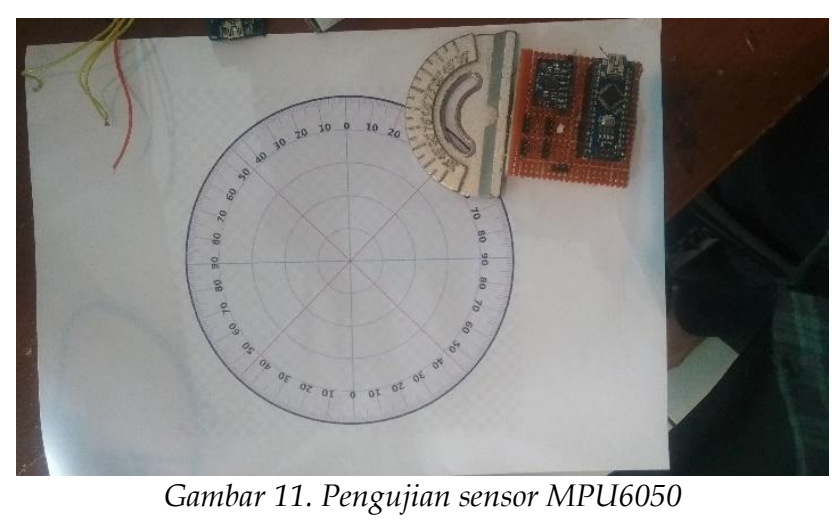


Berikut data hasil pengujian untuk sumbu $\mathrm{x}$ atau sumbu pitch.

Tabel 1. Data hasil perbandingan pembacaan sensor sumbu pitch dengan alat ukur busur derajat

\begin{tabular}{ccc}
\hline $\begin{array}{c}\text { Pitch } \text { busur } \\
\text { (derajat) }\end{array}$ & $\begin{array}{c}\text { Sensor pitch } \\
\text { (derajat) }\end{array}$ & $\begin{array}{c}\text { Error sensor } \\
\text { pitch }\end{array}$ \\
\hline 0 & 0 & 0 \\
30 & 27 & 0.01 \\
45 & 43 & 0.05 \\
60 & 60 & 0.00 \\
75 & 71 & 0.06 \\
90 & 85 & 0.06 \\
\multicolumn{2}{c}{ Rata-rata error } & 0.03 \\
\hline
\end{tabular}

Pada tabel 1, hasil pembacaan sensor pitch memiliki rata-rata error sebesar 0,03. derajat. Hasil pengujian dengan membandingkan pembacaan sensor pitch terhadap nilai busur derajat, data yang didapat masih memiliki nilai error. Untuk menghitung nilai rata-rata error digunakan persamaan 2 .

error sensor pitch $=\left|\frac{\text { pitch busur derajat-sensor pitch }}{\text { Sensor pitch }}\right|$

Berikut data hasil pengujian untuk sumbu y atau sumbu roll.

Tabel 2 Data hasil perbandingan pembacaan sensor roll dengan alat ukur busur derajat

\begin{tabular}{ccc}
\hline $\begin{array}{c}\text { Roll } \text { busur } \\
\text { (derajat) }\end{array}$ & $\begin{array}{c}\text { Sensor roll } \\
\text { (derajat) }\end{array}$ & $\begin{array}{c}\text { Error sensor } \\
\text { roll }\end{array}$ \\
\hline 0 & 0 & 0 \\
30 & 30 & 0 \\
45 & 42 & 0.08 \\
60 & 57 & 0.05 \\
75 & 74 & 0.01 \\
90 & 95 & 0.05 \\
Rata-rata error & 0.03
\end{tabular}

Pada tabel 2 hasil pembacaan sensor roll memiliki rata-rata error sebesar 0,03 derajat. Hasil pengujian dengan membandingkan pembacaan sensor roll terhadap nilai busur derajat, data yang didapat masih memiliki nilai error. Untuk menghitung nilai rata-rata error digunakan persamaan berikut.

$$
\text { error sensor pitch }=\left|\frac{\text { pitch busur derajat-sensor pitch }}{\text { Sensor pitch }}\right|
$$

\subsection{Pengujian Kendali PID}

Pengujian Kendali PID ini bertujuan untuk mengetahui seberapa baik sistem kendali PID dalam mempertahankan kestabilan pesawat tanpa awak tail-sitter pada saat lepas landas hingga mengambang. Sistem kendali akan diuji dengan parameter sebagai berikut: Proportional dengan nilai 2,0, Integral dengan nilai 0,290 dan Derivative dengan nilai 20.

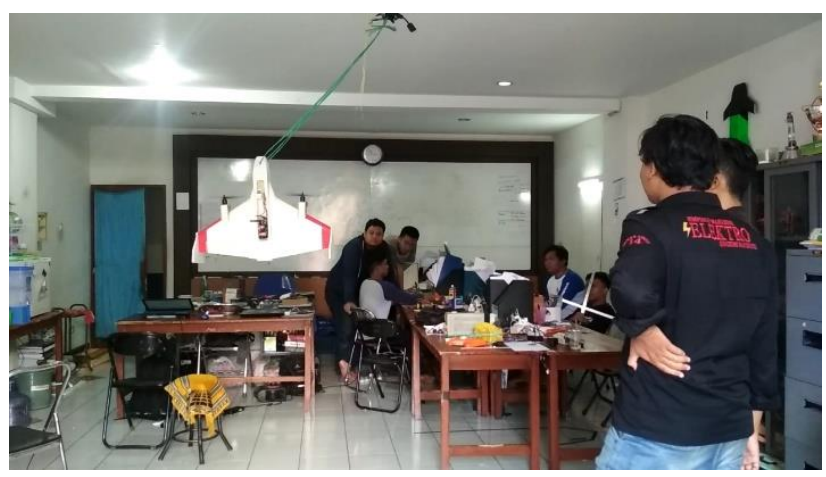

Gambar 12. Pengujian dilakukan di laboratorium Divisi Roket UNIKOM

Pengujian ini dilakukan dengan cara menerbangkan pesawat tanpa awak tail-sitter dengan tali sebagai pengaman lalu dibiarkan terbang mengambang atau hovering seperti pada gambar 12 .

\subsection{Hasil pembacaan pergerakan sudut Pesawat tanpa awak tail-sitter}

Hasil pergerakan sudut pesawat tanpa awak tailsitter di sajikan dalam bentuk grafik seperti terlihat pada gambar 13.

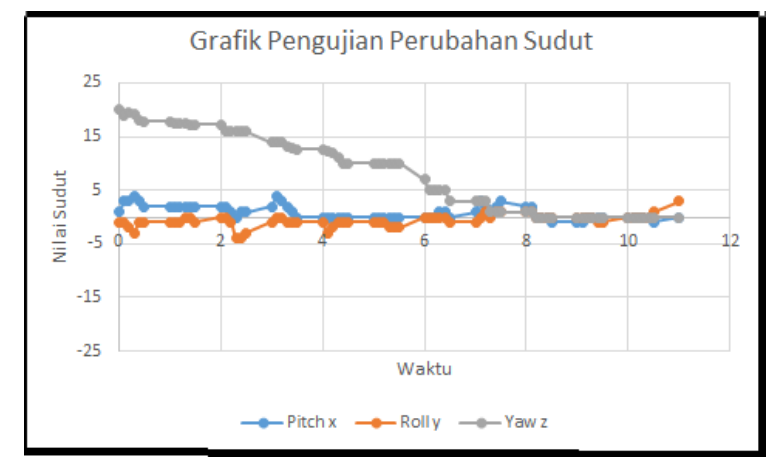

Gambar 13. Grafik hasil kendali PID terhadap perubahan sudut roll, pitch, dan yaw

Berdasarkan pembacaan dan analisa grafik pengujian pada gambar 13, lama pengujian ini adalah selama 12 detik, dari detik pertama hingga akhir, nilai pengukuran pitch dan roll langsung dalam keadaan error steady state atau kesalahan tunak dan mengalami overshoot sebesar 5 derajat pada sumbu Pitch, dan untuk sumbu Roll mengalami overshoot sebesar -5 derajat. Untuk sumbu Yaw dari detik 0-6 mengalami error sebesar 20 derajat dalam kata lain pesawat tail-sitter berputar selama 6 detik dan dari detik 7- 12 nilai error atau putaran berangsur turun dan mengalami error steady state pada detik ke 8 . 


\section{KeSIMPULAN}

Pada pengujian pembacaan sensor IMU MPU6050 pada tabel 3.1 dan tabel 3.2 rata-rata error pada pembacaan sumbu $\mathrm{x}$ (pitch) adalah sebesar 0,03 derajat dan rata-rata error pada pembacaan sumbu y (roll) adalah sebesar 0,03 derajat, maka dapat disimpulkan bahwa pengujian pembacaan sensor MPU6050 memiliki tingkat akurasi yang baik.

Pada pengujian terbang, kendali PID pada sumbu pitch dan Roll berdasarkan analisa grafik pengujian Gambar 3-16 waktu keadaan error steady state terjadi selama 12 detik dengan maksimum overshoot sebesar 5 derajat pada sumbu pitch, untuk sumbu Roll maksimum overshoot sebesar -5 derajat, dan untuk sumbu Yaw keadaan error steady state terjadi selama 5 detik. Berdasarkan hasil tersebut maka dapat disimpulkan bahwa pengujian terbang dengan parameter PID Kp : 2,0, Ki : 0,290, dan Kd : 20, pesawat tanpa awak tail-sitter dapat terbang dan mempertahankan kestabilan nya meskipun masih terjadi steady state error.

\section{DAFTAR PUSTAKA}

[1] H. S. Saroinsong, V. C. Poekoel, and P. D. Manembu, "Rancang Bangun Wahana Pesawat Tanpa Awak (Fixed Wing) Berbasis Ardupilot," J. Tek. Elektro Dan Komput., vol. 7, no. 1, Art. no. 1, Mar. 2018, doi: 10.35793/jtek.7.1.2018.19195.

[2] R. Ritz and R. D'Andrea, "A global controller for flying wing tail-sitter vehicles," in 2017 IEEE International Conference on Robotics and Automation (ICRA), May 2017, pp. 2731-2738, doi: 10.1109/ICRA.2017.7989318.

[3] L. Wu, H. Li, Y. Li, and C. Li, "Position Tracking Control of Tail-sitter VTOL UAV With Bounded Thrust-Vectoring Propulsion System," IEEE Access, vol. 7, pp. 137054-137064, 2019, doi: 10.1109/ACCESS.2019.2942526.

[4] S. Verling, B. Weibel, M. Boosfeld, K. Alexis, M. Burri, and R. Siegwart, "Full Attitude Control of a VTOL tail-sitter UAV," in 2016 IEEE International Conference on Robotics and Automation (ICRA), May 2016, pp. 3006-3012, doi: 10.1109/ICRA.2016.7487466.

[5] R. Bapst, R. Ritz, L. Meier, and M. Pollefeys, "Design and implementation of an unmanned tail-sitter," in 2015 IEEE/RSJ International Conference on Intelligent Robots and Systems (IROS), Sep. 2015, pp. 1885-1890, doi: 10.1109/IROS.2015.7353624.

[6] A. Mulyana and A. Subhan, "Rancang Bangun Sistem Kendali Posisi, Kesetimbangan dan Navigasi untuk Prototipe Nano Satelit," Komputika J. Sist. Komput., vol. 1, no. 1, 2012.
[7] J. Barth et al., "Fixed-wing UAV with transitioning flight capabilities: Model-Based or Model-Free Control approach? A preliminary study," 2018, pp. 1157-1164, Accessed: Dec. 23, 2020. [Online]. Available: http://doi.org/10.1109/ICUAS.2018.8453404.

[8] X. Lyu, H. Gu, J. Zhou, Z. Li, S. Shen, and F. Zhang, "Simulation and flight experiments of a quadrotor tail-sitter vertical take-off and landing unmanned aerial vehicle with wide flight envelope," Int. J. Micro Air Veh., vol. 10, no. 4, pp. 303-317, Dec. 2018, doi: 10.1177/17568293188 13633.

[9] B. Li, W. Zhou, J. Sun, C.-Y. Wen, and C.-K. Chen, "Development of Model Predictive Controller for a Tail-Sitter VTOL UAV in Hover Flight," Sensors, vol. 18, no. 9, Aug. 2018, doi: $10.3390 /$ s18092859.

[10] G. E. Setyawan, E. Setiawan, and W. Kurniawan, "Sistem Kendali Ketinggian Quadcopter Menggunakan PID," J. Teknol. Inf. Dan Ilmu Komput., vol. 2, no. 2, p. 125, Jul. 2015, doi: 10.25126/jtiik.201522144.

[11] W. Alharbi and B. Gomm, "Genetic Algorithm Optimisation of PID Controllers for a Multivariable Process," Int. J. Recent Contrib. Eng. Sci. IT IJES, vol. 5, no. 1, Art. no. 1, Mar. 2017.

[12] M. Zaky, D. Minggu, and G. Sulistiyanto, "Penerapan PID (Proportional Integral Derivative) Untuk Mengontrol Mode Manual Drone Hexacopter," JASIEK J. Apl. Sains Inf. Elektron. Dan Komput., vol. 2, no. 1, Art. no. 1, Jun. 2020, doi: 10.26905/jasiek.v2i1.3944.

[13] T. Sudewo, E. Iskandar, and K. Astrowulan, "Disain dan Implementasi Kontrol PID Model Reference Adaptive Control untuk Automatic Safe Landing pada Pesawat UAV Quadcopter," J. Tek. ITS, vol. 1, no. 1, Art. no. 1, Sep. 2012, doi: 10.12962/j23373539.v1i1.262.

[14] A. Dharmawan and S. Pramudita, "Penerapan Sistem Kendali PID untuk KestabilanTwinTiltrotor dengan Metode DCM," IJEIS Indones. J. Electron. Instrum. Syst., vol. 5, no. 2, Art. no. 2, Oct. 2015, doi: 10.22146/ijeis.7638.

[15] N. Raj, R. Banavar, Abhishek, and M. Kothari, "Attitude Control of Novel Tail Sitter: Swiveling Biplane-Quadrotor," J. Guid. Control Dyn., vol. 43, no. 3, pp. 599-607, Dec. 2019, doi: 10.2514/1.G004697.

[16] Z. Ge and J. Hou, "Design of the control law of longitudinal attitude for Tail-sitter UAV," J. Phys. Conf. Ser., vol. 1298, p. 012027, Aug. 2019, doi: 10.1088/1742-6596/1298/1/012027. 